\title{
DESIGN OF A ROBOT APPLICATION WITH REGARD TO ENERGY EFFICIENCY
}

\author{
Kemajl Stuja, Branko Katalinic, Mohamed Aburaia \& Arbnor Pajaziti
}
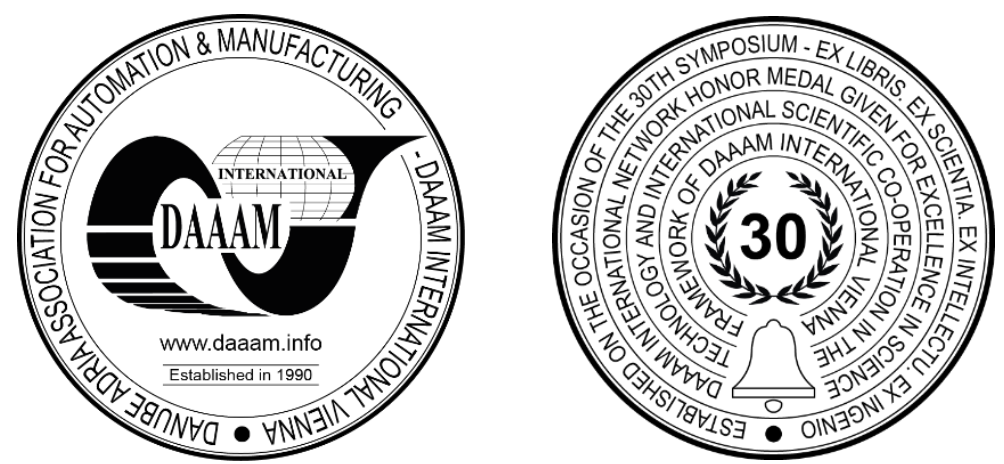

This Publication has to be referred as: Stuja, K[emajl]; Katalinic, B[ranko]; Aburaia, M[ohamed] \& Pajaziti, A[rbnor] (2021). Design of a Robot Application with Regard to Energy Efficiency, Proceedings of the 32nd DAAAM International Symposium, pp.0033-0039, B. Katalinic (Ed.), Published by DAAAM International, ISBN 978-3-902734-33-4, ISSN 1726-9679, Vienna, Austria

DOI: $10.2507 / 32$ nd.daaam.proceedings.005

\begin{abstract}
Design of robotics applications based on energy efficiency is not a new idea or new requirement of industry. Furthermore, the new circumstances of the global warming of the earth's climate system oblige the robotic application designers and system integrators to improve their systems about energy efficiency. Especially robotic systems for palletizing applications, when the Robot moves the parts very quickly, should be improved for the energy efficiency. Inopportunely the implementation of this requirement during design phase often happens partially. In this regard, the designers see the lack of appropriate tools as the cause of this problem as well as missing of physical components during this early project stage. In this context, this works highlights the energy efficiency improvement during design stage using simulation methods/tools for virtual robots. Even in this early stage of the design process, these tools support energy evaluation of different robot moving patterns for different layout concepts. To demonstrate this, a robotic pick-and-place (palletising) application for compost bags is used as a case study. The results of this investigation (energy diagrams) for each concept and scenario are graphically presented and in details discussed. Further research will focus on developing tools for automatic energy check of robotic trajectories within the software user interface.
\end{abstract}

Keywords: Energy efficiency; robot simulation; robot applications; palletizing; design methods.

\section{Introduction}

To remain competitive, robot manufacturer continuously improves their products for power consumptions. Both the electronics and the mechanical system are optimized for an area of application, working range and for an array of payloads. The idea for energy-efficient robotic systems has as well been widely used in the academic world [1]. In this comprehensive publication, almost 100 papers from 1993 to 2017 on the topic of energy consumption have been reviewed and discussed in detail. Two works [2] and [3] are familiar to our publication. Against this, our research is concerned with the design methodology for robotic cells, as well as the design of the flow of materials within the robotic cell, rather than the design of the robot / manipulator itself. The reason is simple: it is not possible for robot manufacturers to produce step less robot sizes or to offer customer-specific solutions as in our investigation [4] but instead of that, they should provide appropriate software tools to improve planning/integration of the robot applications. The design of the robot cell and scheduling of material flow has great potential for energy savings. In this context, it is very important selection of the 
correct manipulator (structure, payload and working range), design of end-effector and periphery components. Amalgamate of all components gives the total energy consumption, which must be improved. Regarding to that, dynamic applications such as palletizing of heavy workpieces are particularly affected, as the total mass moved (including the robot mass) and the workpiece throughput strongly influence the energy consumption. Well-known robot manufacturers ABB, KUKA, Fanuc etc. already offer software simulation tools, which abridge planning, designing, and optimizing of robot systems for energy efficiency. RobotStudio [5] is software tool of ABB and aids programming of robot paths in 3D Environment respectively checking the energy consumptions of robot movements/programmes. This wide-ranging task should be carried out by system integrators or customers. To support this large group of engineers, this paper briefly explains the design methodology for designing palletizing robot applications based on energy efficiency.

\section{Problem Statement- Materials and Methods}

ISO Standard 50001 [6] defines the requirements respectively energy performance only for an entire company. As there is no standard defining explicitly the energy performance of robotic applications, often not all options and possibilities are exhausted in the design of the robotic cell, which can have an impact on energy consumption. Especially small companies because of the lack of corresponding designing departments attempts to find one "quick" solution, without evaluating possible better alternatives in term of energy efficiency. To express the importance of energy performance evaluation a palletizing application for compost bags will be used. This repetitive dynamic robot task can be provided during the design stage of robot cell. The design process and their stages are fully explained in [7]. Safety and Security relationship was discussed at [8] and will be implemented during the design process. For simulation during design process a very powerful software of ABB (RobotStudio) will be used.

\subsection{Requirements of robot application}

The Requirements is the first and the most important task during the design process. In this stage the system integrators should establish the list of customer requirements, initial situations and to define the outgoing functions of the robot applications that must be fulfilled. In our case-study the requirements of the customer are shown below in the table 1 . The table in this work is very short list of customer requirements for the automatizing of bag-application. In the column "demands" are the requirements, which must be fulfilled. In the column of the "wishes" are the features "nice to have", which can be considered, if the engineering costs allows. Work piece is earth composition for flowers. The bag has big volume with small mass (vacuum suction gripper can be used for palletizing/de-palletizing too).

\begin{tabular}{|c|c|c|c|c|}
\hline Requirements & & & Demands & Wishes \\
\hline \multicolumn{5}{|l|}{ Technical Req. } \\
\hline & Workpiece & Weight & Bags $12,5 \mathrm{~kg}$ & Bags $25 \mathrm{~kg}$ \\
\hline & & Content & Compost for flowers & \\
\hline & & Dimension & $500 \mathrm{~mm} \times 300 \mathrm{~mm} \times 120 \mathrm{~mm}$ & \\
\hline & & Flow Rate & $<3,5$ Second / Bag & 3 \\
\hline & Pallets & Form & Euro & \\
\hline & & Layer pattern & See the figure 4 & Different patterns \\
\hline & & Loading/Unloading & Manual by operator & \\
\hline & Machine & Material Workflow & Discontinuously & Continuously \\
\hline \multicolumn{5}{|l|}{ Safety Req. } \\
\hline & Mechanical & & National guidelines/ ISO & \\
\hline & Electrical & & National guidelines/ ISO & \\
\hline \multirow[t]{2}{*}{ Secure Req. } & Software & Authorization & OPC UA & \\
\hline & Hardware & & & \\
\hline Cost Req. & & & $<200000 €$ & \\
\hline
\end{tabular}

Table 1. Short list of customer requirements for palletizing composite bags.

\subsection{Conceptual design - searching for solutions}

The conceptual design stage [7] is a process for generating of ideas, which can be implemented to the system being designed. The entire system can be imaged like black box with inputs/outputs of material, energy and information's (required/wished by customer). Complex systems/tasks will be divided into subsystems/small tasks in order to simplify the design process and to generate many solutions or concepts as possible. The sub-solutions can be placed into the Zwicky "morphological box". Putting the ideas into "morphological box" stimulates creativity and finding of new solutions. After combining the possible solutions, the concept candidates are selected for evaluation [7]. However, the selection process requires a lot of experience and should consider all customer requirements, compliance with security guidelines and technical/economic requirements. Table 2 shows the possible solution candidates. 


\begin{tabular}{|c|c|c|c|c|c|}
\hline & & \multicolumn{4}{|c|}{ Sub-Solutions for the Sub-Functions } \\
\hline & Sub-Functions of Robot cell & Sub-Solution 1 & Sub-Solution 2 & $\cdots$ & Sub-Solution n \\
\hline \multirow{7}{*}{ 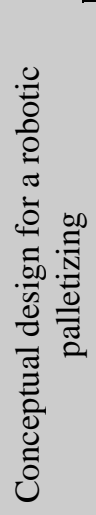 } & "Handling & 6 axis Robot & 4 axis Robot & & Cartesian Robot \\
\hline & Picking & claw gripper & $\begin{array}{c}\text { - vacúum gripper } \\
\text { single }\end{array}$ & & $\begin{array}{c}\text { Vacuum gripper } \\
\text { double }\end{array}$ \\
\hline & Parts Moving & conveyor & $\widehat{A G V}$ & $\ldots$ & Mobile Robot \\
\hline & Part checking & $\begin{array}{c}\text { presence bag } \\
\text { sensors conveyo }\end{array}$ & $\begin{array}{c}\text { résence sensor } \\
\text { gripper }\end{array}$ & $\ldots$ & Vision systems \\
\hline & Safety components & Safety Gates & Light Grids & $\ldots$ & Optical monitoring \\
\hline & 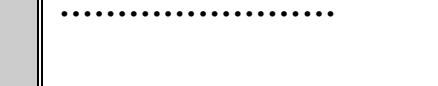 & & & $\cdots \cdots$ & \\
\hline & Authorization & OPC UA & $\begin{array}{l}\text { Windows } \\
\text { embedded }\end{array}$ & $\ldots$ & Linux \\
\hline & $\begin{array}{c}\text { Solution Candidate (SC) - } \\
\text { Variants }\end{array}$ & SC1 & $\mathrm{SC} 2$ & & $\mathrm{SCn}$ \\
\hline
\end{tabular}

Table 2. Simplified and shortened Zwicky - "Morphological box" for creating of solutions -variants [7].

For palletizing of bags, engineers use traditionally the claw grippers. This sub-solution has more technical/economic advantages differing to vacuum suction gripper. For heavy bags the claw-gripper is necessary solution. But thoughts of energy efficiency push the engineers to choose other solutions like a modular vacuum suction gripper, which in contrast to claw-gripper allows maybe gripping of more work pieces at once. If the bags are generally lightweight and offer large permeable suction surfaces a modular vacuum suction gripper can be used for de-palletizing.

On the other hand, palletizing is very high dynamic application. Robot moves continuously the parts very fast from one pick-position to the place-position. Therefore, energy efficiency of the system depends on moving mass. For that reason, it is very significant to find a solution with "lean moving components" and reducing number of movement paths. Thus, idea for using of double suction gripper for picking/placing of two parts at once, reduces for more than $40 \%$ the energy consumption of the entire system. Like in [7] the best solution will be selected considering all requirements of the customer list and will be prepared for the next design stage - preliminary design.

\subsection{Preliminary design}

In this stage of the design the chosen concept from 1.2 will be drafted and digitally modelled for simulation purposes. Here and now is the final moment for risk/vulnerability analysis. As discussed in [7] this analysis affects the costs and technical features of the entire system. On the other hand, different work piece flow scenarios or different grippers cause different safety concepts. In the previous example, the vacuum suction gripper was compared to the claw gripper ([5] models used from RobotStudio library). Using the claw gripper and both filled pallets will be exchanged by the operator, safety concept shown in Fig. 2 can be used. On the other hand, depending on the working environment, this concept cannot be used if the vacuum suction gripper (Fig. 1. b.) has been chosen for the final layout. Should the necessary pneumatic pressure be lost during the rapid robot movement to the "placing"-station, the released bags can fly unhindered through the light grids. This means that the safety concept as in Fig. 2 is not sufficient for the vacuum gripper and must be modified by the safety gates. In this case, replacing the pallets costs more time.

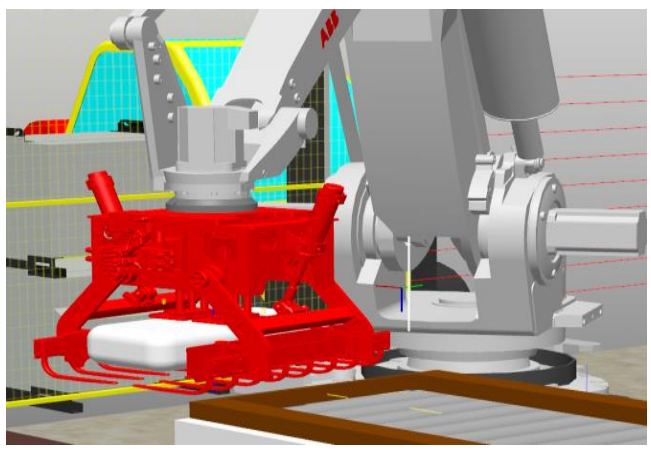

a) Claw gripper [5]

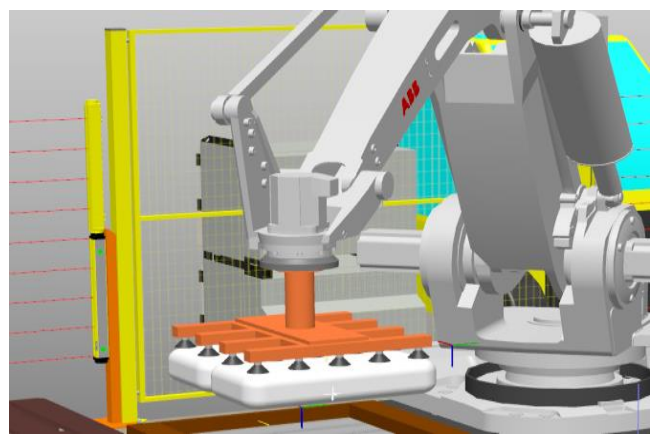

b) Vacuum Gripper [5]

Fig. 1. Possible end-effectors for composite bags. 


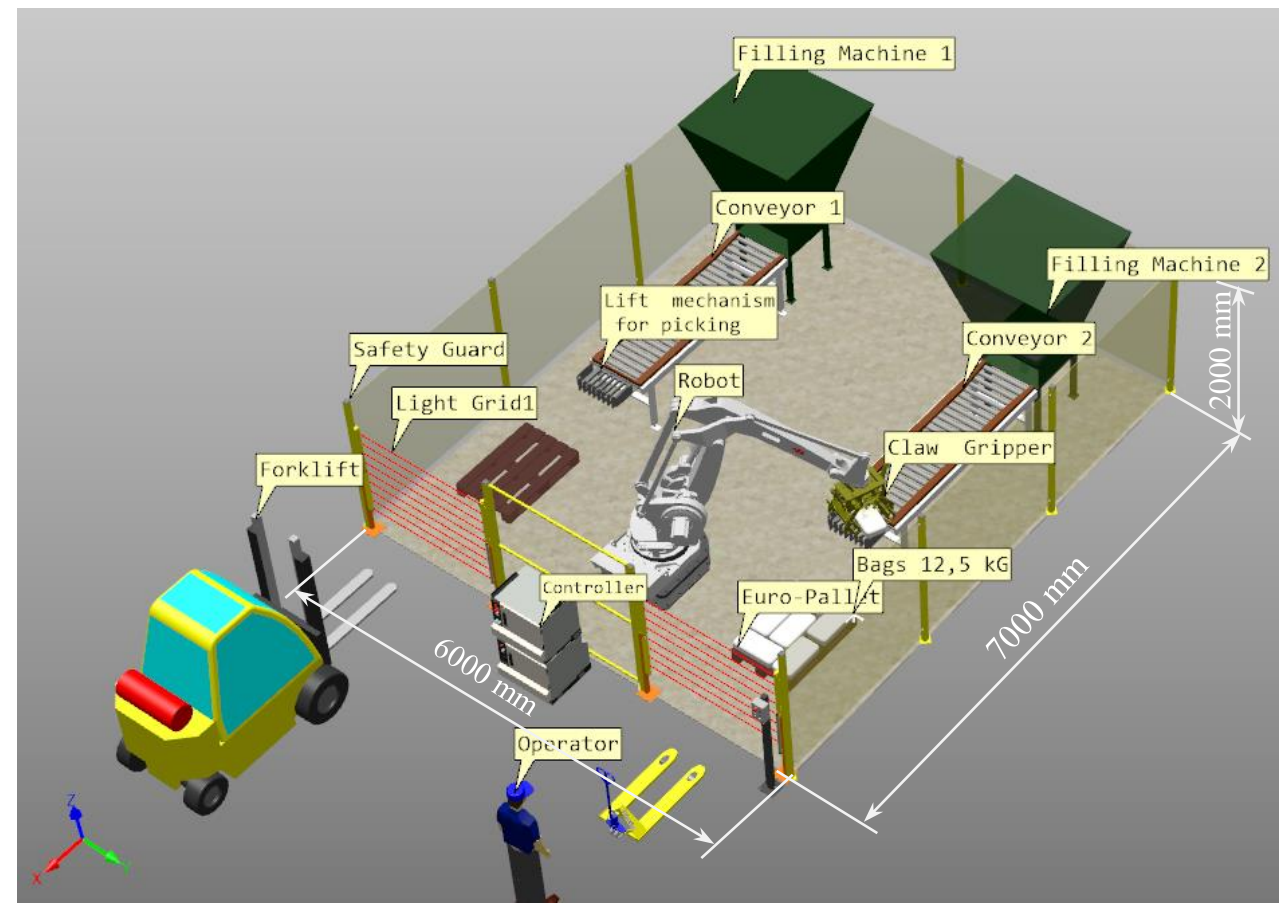

Fig. 2. Layout and simple safety concept for robot cell using claw gripper and discontinuously work piece flow.

\subsection{Final design-layout}

The last task of the system-design is the final design, where the preliminary design should be optimised and all documents, digital models, diagrams, manuals, etc. should be created. In our case study, the simulation layout serves as an output only to answer the customer's requests. Figures 2 and 3 show two similar layouts. The similar part of the layout consists of two filling machines and linear conveyors up to the robot. Depending on the gripper used, an additional lifting/release mechanism is needed to pick up/grip the bags. The first layout (Fig. 2) was designed for the case, when the claw gripper is used. The second layout (Fig. 3) consists of a vacuum suction pad that allows handling of two bags at once. However, there is less safety if the bag falls out from the suction pad. This means that the robotic cell must be enclosed (safety guard) to achieve the required safety level. In both cases, the entire robot cell must be stopped, to exchange pallets. This step can be automated with the exit conveyors for pallets, but this was not what the customer required.

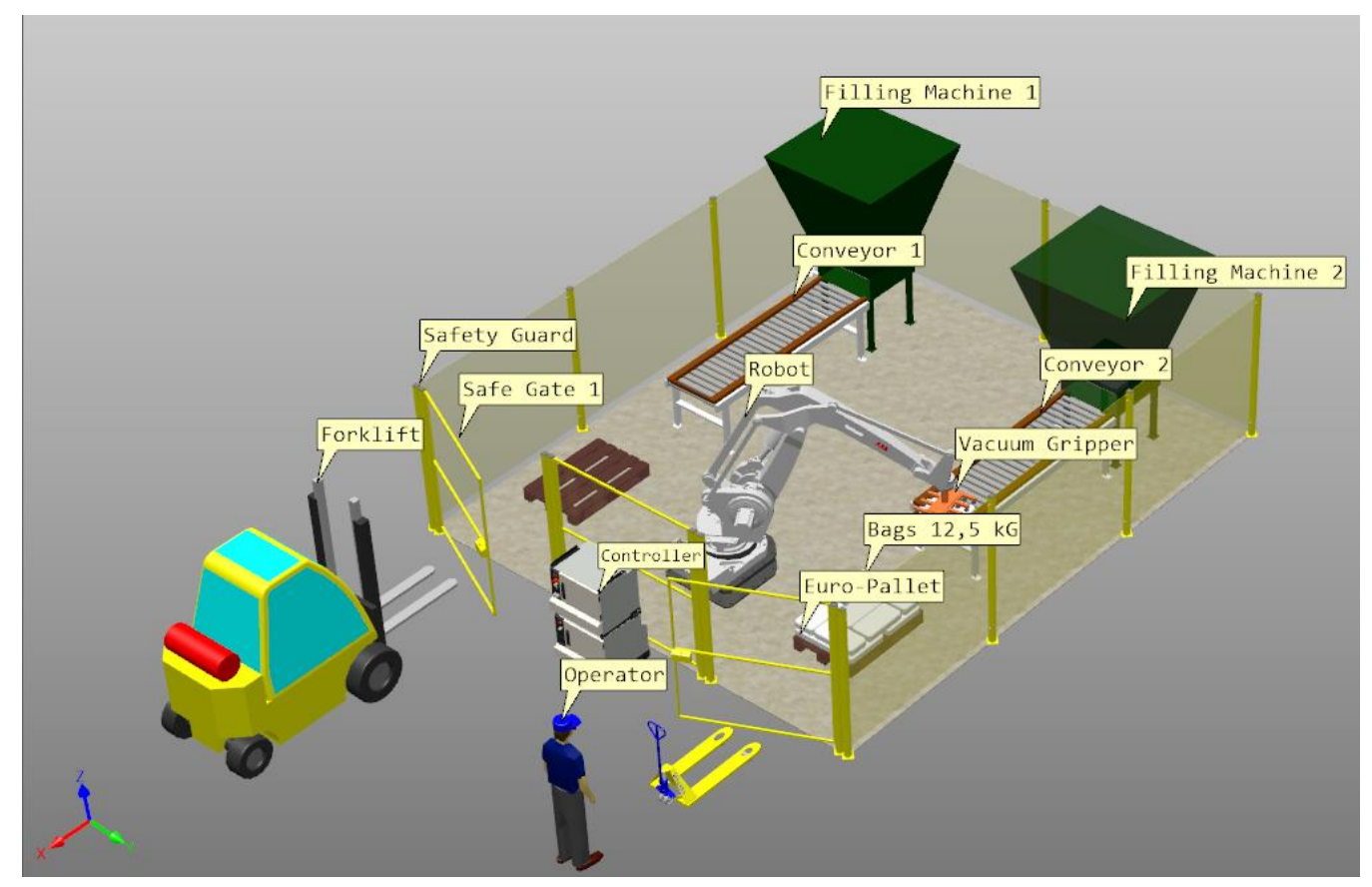

Fig. 3. Layout and simple safety concept for robot cell using vacuum gripper and discontinuously work piece flow. 


\section{Design of experiments, results and discussion}

For the preliminary and final design the simulation results are very important. These results can be used to evaluate the variants and work piece flow scenarios for the preliminary design as well as to optimize the design - final design. Since there are many robot movement parameters that need to be considered, the experimental design can be very extensive. The major moving parameters of robot (for example ABB industrial Robot) are:

- $\quad$ Moving Type (Linear -MoveL, Point to Point - MoveJ etc.)

- Moving velocity and acceleration (TCP - Tool Center Point relative to world or user coordinate system)

- Approach parameters (flying by point or stop point)

- Waiting times (for external events, for vacuum gripping, etc.).

- Robot configurations (Axis positions - where are more than one possible configuration for reaching the target).

Table 3 and Figure 4 show the result of the variant with vacuum suction gripper for a single machine. That means when the first filling machine is working the second will be prepared for the production. In addition, the simulation of the claw gripper is obsolete, since with this end effector only one bag is handled and thus the energy consumption comparing to previous case can be approximately doubled. Table 3 is divided to three columns. The first column shows the scenarios $\mathrm{S}$ from 1 to 16 . The second column are input parameters (variables). The third column represents the major results (output parameters). The flow rate of the work pieces is constant $1 \mathrm{Bag} / 3$ seconds for single machine and was used from the customer requirements (table 1), respectively acts as time constraint for the simulation. For parallel working machines and continuously work piece flow, robot must move alternately from one machine to another. This solution would be inefficient. The second column is moving type between pick and place stations. Linear movement is not efficient (S16). Third column is tool-center-point (TCP) velocity relative to work-object-coordinate system. Fourth column is approach parameter (flying by point) for "air" targets. That means by z100, robot-TCP $100 \mathrm{~mm}$ before reaching the programmed target, moves toward next programmed target (flying around the point to truncate the distance respectively to spare brakes, to reduce energy consumption's, etc.). This parameter can be applied for the "air" targets between stations. Pick and Place targets remains to "fine" zone. They are stop targets. The last two columns are two output parameters: cycle time including steady state and waiting times. The last column (from left) shows the energy consumption for different input parameters. Scenario 1 to 5 (S1 to S5) take too much time respectively they are inefficient since fine zone (stop points) are used for all targets. Scenarios 6 and 11 are disqualified, then they take too much time and cycle time required by customer cannot be achieved. Scenario 7 and 12 is possible with risk tendency: queues (conveyors) to become overflowed. Scenario 8 or 13 can be used for the final programming. By remaining scenarios robot must wait for work pieces and thus consumes more energy.

\begin{tabular}{|c|c|c|c|c|c|c|}
\hline \multirow{2}{*}{$\begin{array}{c}\text { Scenario } \\
\text { (S) }\end{array}$} & \multicolumn{4}{|c|}{ Input Parameters } & \multicolumn{2}{|c|}{ Output Parameters } \\
\hline & $\begin{array}{c}\text { Flow Rate } \\
\text { [Bag / s] }\end{array}$ & $\begin{array}{c}\text { Moving } \\
\text { Type }\end{array}$ & $\begin{array}{c}\text { TCP } \\
\text { Velocity } \\
{[\mathrm{mm} / \mathrm{s}]}\end{array}$ & $\begin{array}{c}\text { TCP Zone } \\
\text { [mm] }\end{array}$ & $\begin{array}{c}\text { Cycle Time } \\
\text { including Waiting } \\
{[\mathrm{s}]}\end{array}$ & $\begin{array}{c}\text { Energy } \\
\text { Consumption } \\
\text { (Joule) }\end{array}$ \\
\hline S1 & 3 & PTP* & 1000 & fine & Not possible & \\
\hline S2 & 3 & PTP & 2000 & fine & $02: 24$ & 98209,2 \\
\hline S3 & 3 & PTP & 3000 & fine & 02:07 & 128484,2 \\
\hline S4 & 3 & PTP & 4000 & fine & 02:07 & 149044,5 \\
\hline S5 & 3 & PTP & 5000 & fine & 02:07 & 159723,2 \\
\hline S6 & 3 & PTP & 1000 & $\mathrm{z} 100 * *$ & Not possible & \\
\hline S7 & 3 & PTP & 2000 & $\mathrm{z} 100$ & $02: 12$ & 93439,3 \\
\hline S8 & 3 & PTP & 3000 & z100 & $01: 57$ & 122288,0 \\
\hline S9 & 3 & PTP & 4000 & z100 & 01:57 & 142517,5 \\
\hline S10 & 3 & PTP & 5000 & $\mathrm{z} 100$ & 01:57 & 151792,5 \\
\hline S11 & 3 & PTP & 1000 & $\mathrm{z} 200 * *$ & Not possible & \\
\hline S12 & 3 & PTP & 2000 & $\mathrm{z} 200$ & 02:05 & 93407,24 \\
\hline S13 & 3 & PTP & 3000 & $\mathrm{z} 200$ & $01: 57$ & 122167,8 \\
\hline S14 & 3 & PTP & 4000 & $\mathrm{z} 200$ & 01:57 & 142412,0 \\
\hline S15 & 3 & PTP & 5000 & $\mathrm{z} 200$ & 01:57 & 151799,2 \\
\hline S16 & 3 & Linear & 5000 & $\mathrm{z} 200$ & $01: 57$ & 188989,2 \\
\hline
\end{tabular}

*) Robot moves between two stations (long distances) with MoveJ (PTP-Point to point) and flying by. End-positions "Pick" or "Place" are linear. **) End-positions "Pick" or "Place" remains with "fine" zone.

Table 3. Results of energy consumption for Layout (vacuum gripper) moving Robot with different parameters. 


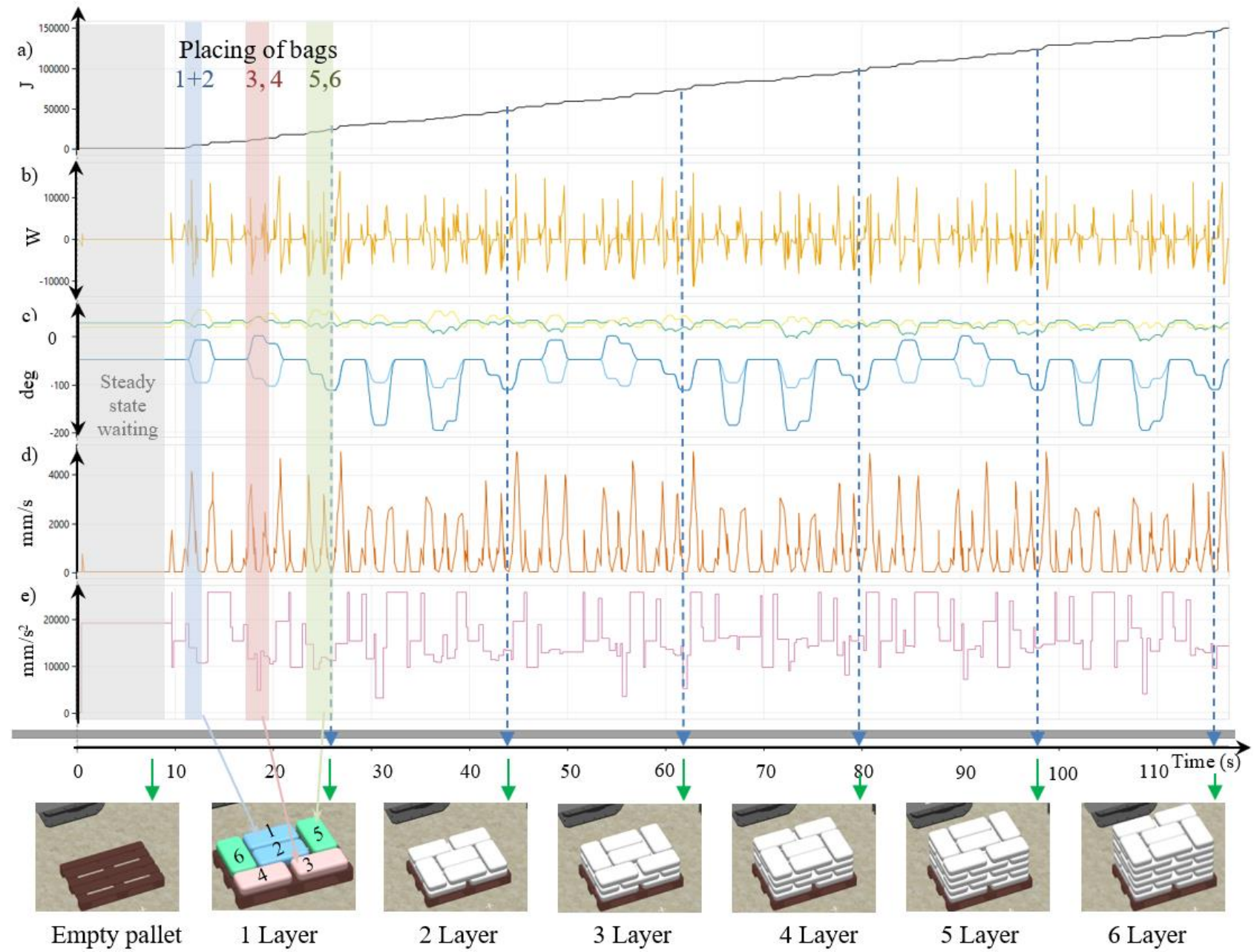

Fig. 4. Energy consumption of virtual robot for scenario S10-Table 3 and palletizing patterns.

Fig. 4 shows the energy consumption for scenario S10 (see Table 3 for more information). For each scenario there is a different graph. Abscise shows the time needed to palletize 6 layers. There are 36 bags in total $=6$ layers $x 6$ bags. The even patterns 1,3,5 or the odd patterns 2, 4, 6 are the same depending on the customer's request. Grey pillar in diagram shows steady state - waiting time of Robot for arriving of first two bags (can be omitted). The blue, red and green columns show the time needed to place two bags, with the blue column being narrower as two bags (1 and 2) are placed at the same time. Furthermore, Fig. 4 also shows the following: Fig. 4 a) shows the cumulative energy consumption of virtual robot during the time (expressed in Joule - J). Fig. 4 b) shows the work needed for different robot motion (expressed in Watt $-\mathrm{W}$ ). Fig. $4 \mathrm{c}$ ) shows the Joint $(\mathrm{J})$ angles during robot motion, where colours mean: $\square \mathrm{J} 1, \square \mathrm{J} 2, \square \mathrm{J} 3$ and $\square \mathrm{J} 4$ (expressed in degrees). The second and third Joint moves very smoothly. The first and fourth Joints are more dynamically during the time. Fig. 4 d) shows the velocity as well Fig. 4 e) shows the acceleration of tool centre point (TCP) relating to work object coordinate system. To find the optimal velocity for the cycle time this diagram is very important. In diagram are many speed profiles like trapezoid, triangle and truncated triangle. Trapezoid speed profile means that the distance between distance AD (Fig. 5 a) programmed speed can be reached. Triangle profile (Fig. 5 b) shows that the programmed speed can be reached only at the point B. Truncated triangle profile (Fig. 5 b yellow shape) shows that the programmed speed cannot be reached, since distance AD is too small. Furthermore, this programming style, would mechanically strains the structure of manipulator and should therefore be avoided.
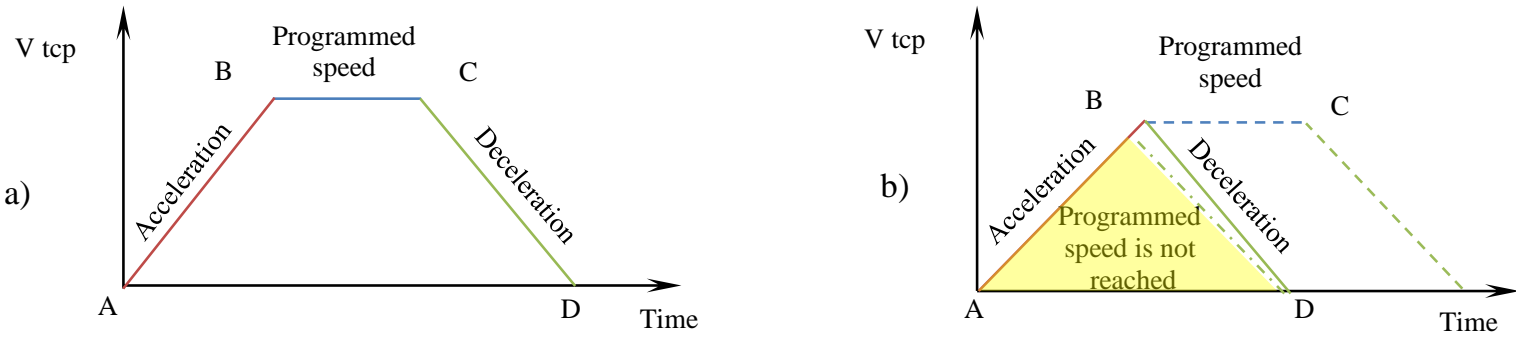

Fig. 5. Velocity (speed) profiles of the Robot TCP: a) Trapezoid, b) Triangle resp. truncated triangle (yellow shape). 


\section{Summary, Conclusion and outlook}

Design of robot applications is a comprehensive engineering work. To find and work out an optimal solution for these kinds of applications, interdisciplinary knowledge is necessary. Especially for the design of highly dynamic material flow applications, the software tools are necessary. A methodical approach is very significant for finding a creative as well as the optimal solutions, in term of energy efficiency. In this work, a combination of two methodological approaches is used: VDI-2221 for mechanical design and VDI-2206 for mechatronic design. It has been shown (headings 1.1 to 1.4) that the use of these approaches makes efficient and shortens engineering work. Moreover, these methods allow to find and evaluate creative solutions (claw- and vacuum -gripper). On the other hand, the simulation tool supported the design of various robot cell layouts with different material flow scenarios using virtual models at a very early stage of the project. By simulating of 16 scenarios in very shortly time, this simulation tool has proven its worth. Different concepts for the work piece flow in the robotic cell result in different energy profiles.

According to the customer conditions, a concept of two parallel filling machines with robot in the centre was chosen. Switching on the machines one after the other when the pallet is full is the best variant in terms of energy consumption by discontinuously work piece flow. Rearrangements of machines and conveyor belts to reduce / optimize the throughput time of the work pieces (bags) are not desired by the customer and for that reason are not investigated. Among others, the simulation results have shown the rocky relationship between safety and the design process. For Example: depending on used gripper (claw or vacuum suction) the safety concept will be different, causing possibly additional cost. Therefore, during the designing process is very important the consideration of safety/security as well as energy efficiency of robot application. The last part significantly affects the final design, base cost for the robot cell and running cost. According to the simulation results, it was confirmed once again that the shortest robot paths (linear paths) are not less energy consuming (Scenario S16, Table 3). Hence, linear movement was used only between offset and final targets (Pick /Place targets). Using Point-to-Point movement type and variation approach parameters (fly by point) was possible to reduce energy consumption rep. to reduce the total cycle time (Scenario S6 to S15, Table 3). Another advantage of simulation was the option for analysing of speed profiles (shown in fig 4). It has been shown that the cause of the after-swinging of mechanical structure (manipulator) is the truncated triangle profile. Although this phenomenon cannot be observed in the animation, the diagram clearly shows that the programmed speed of the TCP cannot be reached. That means, for short distances, the high speeds are not useful and should be avoided.

Further research should focus on add-ins for the simulation software to automatically analyse robot trajectories/trajectories. Highlighting robot trajectories with different colours (e.g. green for trajectories with lower energy consumption) directly in the simulation software user interface would help designers and reduce development time.

\section{Acknowledgments}

We would like to thank the company ABB Robotics in Austria for providing the software and for equipping the laboratory at the Vienna University of Applied Sciences with robots. We would like to express our special thanks of gratitude to our sponsor MA23 Vienna and to "TÜV -Austria Gruppe" for the technical support.

\section{References}

[1] Carabin, G; Wehrle, E. \& Vidoni, R. (2017). A Review on Energy-Saving Optimization Methods for Robotic and Automatic Systems, Robotics 2017, 6, 39; doi:10.3390/robotics6040039 pp. 1-21. www.mdpi.com/journal/robotics.

[2] Paes, K; Dewulf, W.; Vander Elst, K.; Kellens, K. \& Slaets P. (2014). Energy Efficient Trajectories for an Industrial ABB Robot. 21st CIRP Conference on Life Cycle Engineering, Volume 15, pp105-110 ISSN 2212-8271, DOI: 10.1016/j.procir.2014.06.043.

[3] Liu, A; Liu, H.; Yao, B.; Xu, W. \& Yang, M. (2018). Energy consumption modeling of industrial robot based on simulated power data and parameter identification. SAGE Publications, Advances in Mechanical Engineering, Vol. 10(5), pp 1-11 https://doi.org/10.1177/1687814018773852.

[4] Stuja K., Bruqi, M., Markl E. \& Aburaia, M. (2016). Lightweight 4 -Axis Scara Robot for Education and Research, Proceedings of the 27th DAAAM International Symposium, pp. 0102-0108, B. Katalinic (Ed.), Published by DAAAM International, ISBN 978-3-902734-08-2, ISSN 1726-9679, Vienna, Austria.

[5] https://new.abb.com/products/robotics/robotstudio. ABB AG. Accessed on: 2021-08-21.

[6] ISO 50001(2018). Energy management systems - Requirements with guidance for use (ISO 50001:2018).

[7] Stuja, K.; Poszvek, G.; Walter, W. \& Markl, E. (2018). Integrated Method for The Design and Evaluation of Safety \& Secure Manufacturing Systems, Proceedings of the 29th DAAAM International Symposium, pp.157-163, B. Katalinic (Ed.), Published by DAAAM International Vienna, ISBN 978-3-902734-20-4, ISSN 1726-9679, Vienna, Austria DOI: 10.2507/29th.daaam.proceedings.022.

[8] TÜV Austria Gruppe (2018). Sicherheit in der Mensch-Roboter-Kollaboration, Fraunhofer Austria Research GmbH, pp. 23-25, White Paper, No.3, March 2018. 